\title{
PENGARUH KEPEMIMPINAN, MOTIVASI KERJA DAN KOMPENSASI TERHADAP KINERJA (STUDI PADA PEGAWAI KANTOR IMIGRASI KELAS II KARAWANG)
}

\author{
Deden Santa Winata Kusumah, Eman Sulaeman, Rahmat Hasbullah \\ Universitas Singaperbangsa Karawang \\ deden.swk@gmail.com
}

\begin{abstract}
ABSTRAK
Penelitian ini bertujuan untuk mengetahui, menjelaskan dan menganalisis Kepemimpinan, Motivasi Kerja Dan Kompensasi Terhadap Kinerja Pegawai serta pengaruh parsial dan simultan Kepemimpinan, Motivasi Kerja Dan Kompensasi Terhadap Kinerja Pegawai Pada Kantor Imigrasi Kelas II Karawang. Jumlah sampel yang diambil sebanyak 55 pegawai dengan teknik sampling jenuh. Tesis ini diharapkan dapat memberikan sumbangan bagi pengembangan bidang manajemen khususnya manajemen sumber daya manusia. Metode penelitian yang digunakan penulis dalam penulisan ini menggunakan metode deskriptif dan verifikatif, dari hasil analisis data penelitian diperoleh beberapa kesimpulan sebagai berikut: (1) Kinerja Pegawai pada Kantor Imigrasi Kelas II Karawang sudah baik. (2) 2.Kepemimpinan pada Kantor Imigrasi Kelas II Karawang sudah baik.(3) Motivasi Kerja pada Kantor Imigrasi Kelas II Karawang yang diberikan kepada pegawai sudah baik. (4) Kompensasi pada Kantor Imigrasi Kelas II Karawang sudah baik (5) Terdapat pengaruh parsial antara Kepemimpinan terhadap Kinerja sebesar $27.6 \%$ dan terdapat pengaruh parsial antara Motivasi Kerja terhadap Kinerja $27.4 \%$ kemudian pengaruh parsial Kompensasi Terhadap Kinerja 21.9\% . (6) Kepemimpinan, Motivasi Kerja dan Kompensasi secara simultan berpengaruh positif dan signifikan terhadap Kinerja Pegawai. Total pengaruh yang disebabkan Kepemimpinan (X1), Motivasi Kerja (X2) dan Kompensasi (X3) terhadap Kinerja Pegawai (Y) yaitu sebesar 0,769 atau 76,9\% adapun pengaruh variabel lain diluar model adalah sebesar 0,231 atau 23,1\%.
\end{abstract}

Kata Kunci: Kepemimpinan, Motivasi, Kompensasi, Kinerja

\section{A. PENDAHULUAN}

Sumber daya manusia salah satu sumber daya yang ada dalam organisasi memiliki peranan penting dalam keberhasilan pencapaian tujuan organisasi. Sumber daya manusia menggunakan sumber daya-sumber daya lain yang dimiliki oleh organisasi dalam rangka mencapai tujuan. Pengelolaan dan pengembangan sumber daya manusia merupakan suatu investasi bagi perusahaan karena diperlukan biaya untuk mendukung hal tersebut, namun sejalan dengan hal tersebut, manfaat yang didapat oleh perusahaan juga besar karena pegawai yang dimiliki menjadi profesional dan handal dalam mengerjakan segala pekerjaan di perusahaan tersebut. Dengan demikian pengelolaan dan pengembangan sumber daya manusia menjadi penentu keberhasilan dalam suatu organisasi. Sumber daya manusia juga mempunyai peran utama dalam setiap kegiatan perusahaan, Bertahan dan meningkat nya kinerja perusahaan tergantung dari sumber daya manusia yang bekerja di dalamnya 
Dalam mewujudkan hal tersebut kantor Imigrasi Kelas II karawang berusaha untuk terus meningkatkan kinerja para pegawainya agar menjadi sumber daya manusia yang profesional, memiliki kualitas serta integritas yang tinggi.

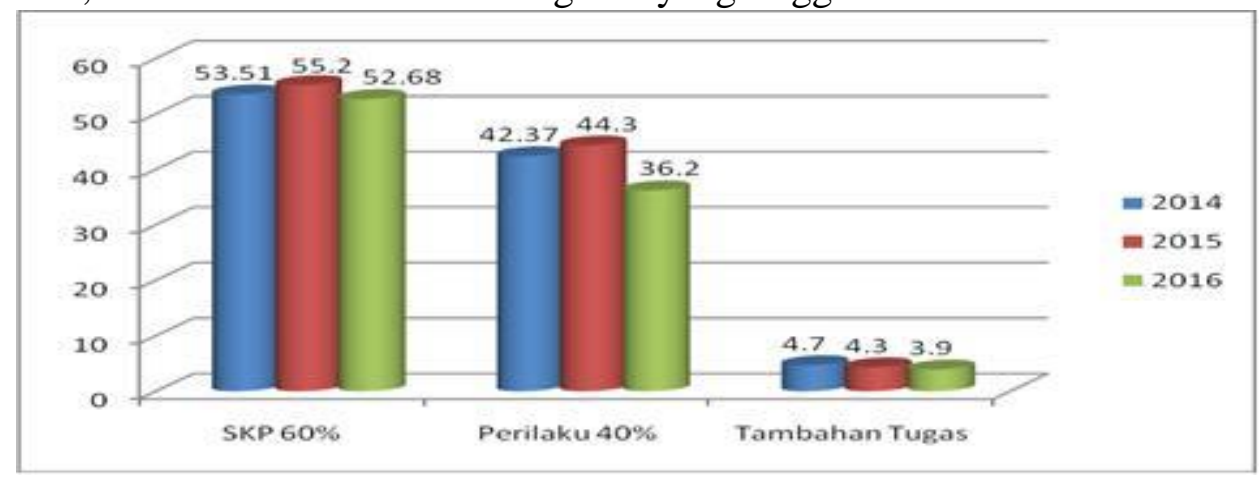

Sumber: Imigrasi Karawang diolah 2017

\section{Gambar 1}

Data Kinerja Pegawai Kantor Imigrasi Karawang

Berdasarkan data di atas dapat ditarik kesimpulan bahwa nilai terendah untuk penilaian kinerja pegawai Imigrasi Karawang pada tahun 2016 terendah dibanding tahun 2014 dan 2015. Hal ini membuktikan bahwa kinerja pegawai Imigrasi masih rendah.

Rendahnya kinerja pegawai diduga Karena rendahnya kepemimpinan yang ada. Kepala Imigrasi sebagai pimpinan tertinggi sangat berpengaruh dalam menentukan organisasi yang dipimpinnya. Kepemimpinan yang baik harus dapat mengupayakan peningkatan kinerja pegawainya. Penelitian Rahmat Sugianto (2010) menyatakan bahwa Terdapat pengaruh kepemimpinan manajerial terhadap kinerja. Senada dengan penelitian Susiati Purwaning Utami (2010) dalam penelitiannya menyatakan bahwa terdapat hubungan positif kuat dan signifikan antara kepemimpinan terhadap kinerja. Berikut adalah data hasil penelitian pendahuluan melalui penyebaran kuesioner kepada 30 responden pada Kantor Imigrasi karawang.

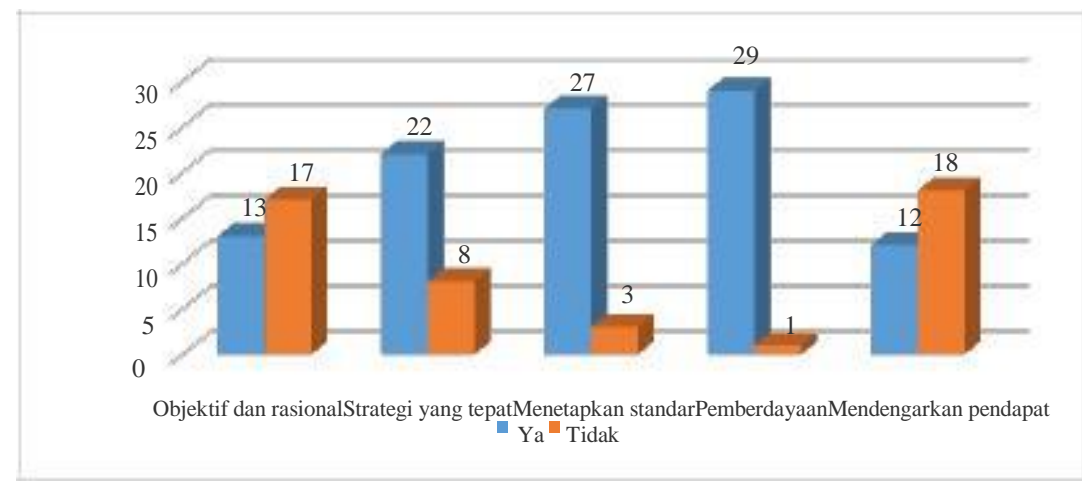

Sumber: Penelitian Pendahuluan 2017

Gambar 2

Hasil Penelitian Pendahuluan Kepemimpinan

Berdasarkan data di atas dapat ditarik kesimpulan bahwa beberapa pegawai merasa pemimpin kurang objektif dan rasional serta pendapat yang diberikan oleh pegawai kurang begitu diperhatikan. Hal ini membuktikan bahwa kepemimpinan masih rendah.

Rendahnya kinerja juga diduga karena rendahnya motivasi kerja pegawai. Windy Aprilia Murty dan Gunasti Hudiwinarsih (2012) dalam penelitiannya menyatakan bahwa 
motivasi berpengaruh positif dan signifikan terhadap kinerja pegawai. Selanjutnya hasil penelitian Ririvega kasenda (2013) menyatakan bahwa Motivasi berpengaruh signifikan terhadap kinerja pegawai nilai koefisien adalah positif. Berikut adalah data hasil penelitian pendahuluan mengenai motivasi kerja melalui penyebaran kuesioner kepada tiga puluh orang responden.

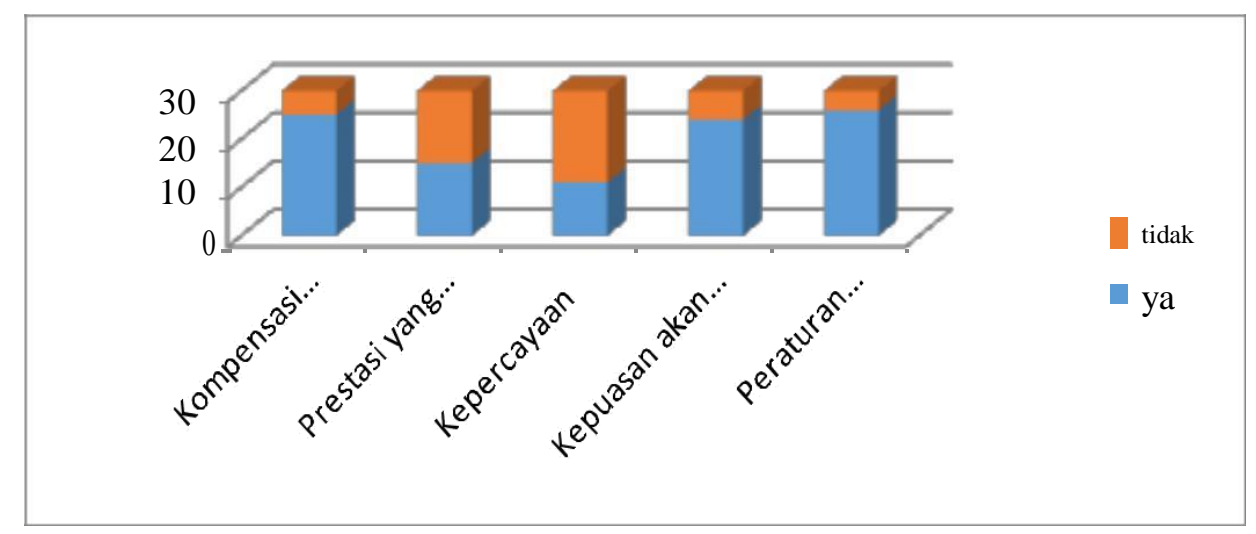

Sumber: Hasil Penelitian Pendahuluan 2017

Gambar 3

Hasil Penelitian pendahuluan Motivasi Kerja

Berdasarkan data di atas dapat diatarik kesimpulan bahwa masih ada beberapa pegawai yang merasa bahwa kurang diberikan kepercayaan untuk yang penuh dalam menjalankan tugas sehari-hari serta kurang didorong untuk mencapai prestasi yang lebih tinggi.

Rendahnya kinerja diduga karena rendahnya kompensasi yang diterima. Kemudian didukung oleh penelitian yang dilakukan oleh Didik Hadiyatno (2012) menyatakan bahwa kompensasi mempunyai pengaruh terhadap kinerja karyawan. Sejalan dengan penlitian Agiel Puji Damayanti, Susilaningsih, Sri Sumaryati (2013) dalam penelitiannya menyatakan bahwa ada pengaruh yang signifikan kompensasi terhadap kinerja karyawan. Kemudian penelitian yang dilakukan oleh Ni Ketut Ayu Juli Astuti dan I Nyoman Sudharma (2013) menyatakan bahwa kompensasi berpengaruh positif dan signifikan terhadap kinerja karyawan. Ririvega Kasenda (2013) dalam penelitiannya menyatakan bahwa kompensasi berpengaruh signifikan terhadap kinerja karyawan dengan nilai koefisien adalah positif. Kemudian didukung juga oleh penelitian yang dilakukan oleh Ferry Setiawan dan A. A. Sg. Kartika Dewi (2014) menyatakan bahwa kompensasi berpengaruh positif dan signifikan tehadap secara langsung terhadap kinerja. Berikut adalah hasil penelitian pendahuluan terhadapa 30 orang responden pada kantor imigrasi karawang

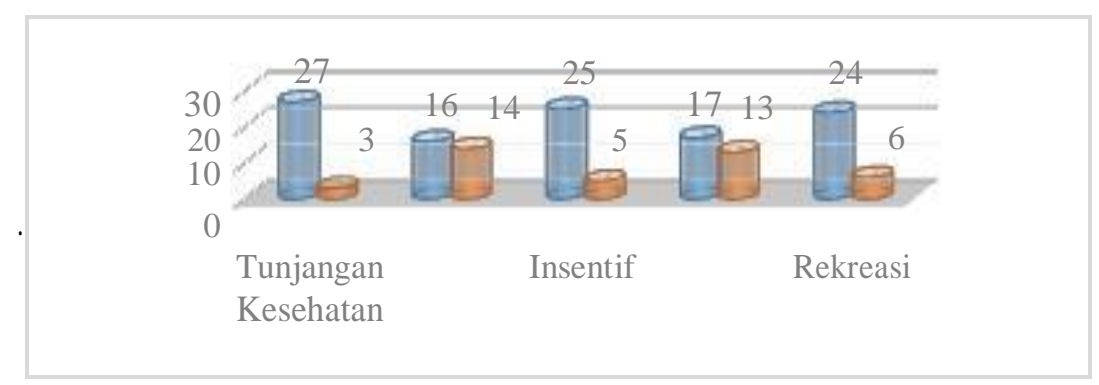

Sumber: Hasil penelitian pendahuluan 2017

Gambar 4 


\section{Hasil Penelitian Pendahuluan Kompensasi}

Berdasarkan data di atas dapat ditarik kesimpulan bahwa masih ada pegawai yang belum mendapatkan beasiswa pendidikan dan fasilitas penunjang dalam pekerjaan.

\section{B. TINJAUAN PUSTAKA}

\section{Kinerja Pegawai}

Istilah kinerja berasal dari kata job performance atau Actual Performance Menurut Anwar Prabu Mangkunegara (2011:67), mengemukakan bahwa "Kinerja berasal dari kata job performance atau actual performance (prestasi kerja atau prestasi sesungguhnya yang dicapai seseorang).Pengertian kinerja adalah hasil kerja secara kualitas dan kuantitas yang dicapai oleh seorang pegawai dalam melaksanakan tugasnya sesuai dengan tanggung jawab yang diberikan kepadanya".

Menurut Lijan Poltak Sinambela, (2012:5) Kinerja adalah pelaksanaan suatu pekerjaan dan penyempurnaan pekerjaan sesuai dengan tanggung jawabnya sehingga dapat mencapai hasil sesuai dengan yang diharapkan.

Sedangkan kinerja menurut Bernardin dalam Sudarmanto (2014:8), kinerja merupakan catatan hasil yang yang diproduksi atas fungsi pekerjaan tertentu selama periode tertentu.

Menurut Harbani Pasolong (2011:176) Kinerja pegawai adalah banyaknya upaya yang dikeluarkan individu dalam mencurahkan tenaga sejumlah tertentu pada pekerjaan. Menurut Wibowo (2012: 8)

Kinerja sebagai proses komunikasi yang dilakukan secara terus menerus dalam kemitraan antara karyawan dengan atasan langsungnya. Proses komunikasi ini meliputi kegiatan membangun harapan yang jelas serta pemahaman mengenai pekerjaan yang akan dilakukan.

Menurut Malayu S.P Hasibuan (2008:94) Kinerja adalah suatu hasil yang dicapai seseorang dalam melaksanakan tugas-tugas yang dibebankan kepadanya berdasarkan atas kecakapan, pengalaman dan kesungguhan serta waktu.

\section{Kepemimpinan}

Pemimpin merupakan unsur vital dalam sebuah organisasi, dan dalam setiap kegiatannya pemimpin di tuntut untuk memiliki kemampuan yang baik, hal tersebut terjadi karena para pemimpin membawahi sekelompok orang dalam melaksanakan tugas sehingga dapat mencapai tujuan tugas tersebut. Dengan kepemimpinan yang baik, maka peran bawahan akan berjalan dengan baik pula.

Menurut Siswanto (2010:154), pengertian kepemimpinan adalah:

Sifat dan perilaku untuk mempengaruhi para bawahannya agar mereka mampu bekerja sama sehingga membentuk jalinan kerja yang harmonis dengan pertimbangan aspek efisien dan efektif untuk mencapai tingkat produktivitas kerja sesuai dengan yang telah ditetapkan.

Adapun pendapat lain yang menjelaskan mengenai kepemimpinan Menurut Ulber Silalahi (2012:310) yang mengemukakan bahwa kepemimpinan adalah "Tindakan mempengaruhi perilaku seseorang atau sekelompok orang kearah pencapaian tujuan-tujuan”.

Selanjutnya Menurut Husaini Usman (2011:282) "Kepemimpinan merupakan ilmu dan seni memengaruhi orang atau kelompok untuk bertindak seperti yang diharapkan untuk mencapai tujuan secara efektif dan efisien". 
Dengan demikian Kepemimpinan adalah Proses seseorang dalam mempengaruhi orang lain atau kelompok agar dapat mengikuti apa yang di inginkannya dengan menggunakan aturanaturan dan norma-norma yang berlaku, sehingga tercipta tujuan yang di inginkannya secara efektif dan efisien.

\section{Motivasi}

Menurut Hasibuan (2010:92) Mengemukakan motivasi berasal dari kata latin movere yang berarti menggerakan atau mendorong. Didalam konsep manajemen atau konsep manajemen perilaku kata motivasi didefinisikan sebagai semua upaya untuk memunculkan dari dalam semangat orang lain (bawahan) agar mau bekerja keras guna mencapai tujuan organisasi melalui pemberian atau penyediaan pemuasan kebutuhan mereka. Seorang manajer harus mengenal konsep motivasi agar manajer juga memahami bahwa bawahan juga orang (manusia) seperti dirinya yang mempunyai martabat, harga diri, kepribadian, emosi, keyakinan, kepercayaan, keinginan, dan harapan.

Menurut pendapat yang dikemukakan oleh Gitosudarmo (2011:134) motivasi adalah:

"Suatu faktor yang mendorong seseorang untuk melakukan suatu aktivitas tertentu, oleh karena itu motivasi seringkali diartikan sebagai faktor pendorong perilaku seseorang. Pendorong perilakau seseorang biasanya kebutuhan serta keinginan yang hendak dicapai."

Menurut Grant (2008:48-58) mengatakan bahwa "motivasi adalah hasrat untuk berupaya guna memberikan manfaat bagi orang lain, menunjukan tingkat dimana perilaku para karyawan berhasil di dalam memberikan kontribusi terhadap tujuan-tujuan organisasi." Menurut Wilson Bangun (2012:313), bahwa motivasi adalah suatu tindakan untuk mempengaruhi orang lain agar berperilaku secara teratur.

Menurut Stephen P. Robbins, dkk (1999) dalam Winardi (2011:2) "Motivasi adalah kesediaan untuk melaksanakan uapaya tinggi untuk mencaapai tujuan-tujuan keorganisasian, yang dikondisikan oleh kemampuan upaya untuk memenuhi kebutuhan individual tertentu."

Menurut Gray, dkk (1984) dalam Winardi (2011:2) "Motivasi merupakan hasil sejumlah proses yang bersifat internal atau eksternal bagi seorang individu, yang menyebabkan timbulnya sikap entusiasme dan persistensi dalam hal melaksanakan kegiatan-kegiatan tertentu."

Sedangkan menurut Siagian (1995) dalam Edy Sutrisno (2014:110)

"Motif adalah keadaan kejiwaan yang mendorong, mengaktifkan, atau menggerakkan dan motif itulah yang mengarahkan dan menyalurkan perilaku, sikap, dan tindak tanduk seseorang yang selalu dikaitkan dengan pencapaian tujuan, baik untuk organisasi maupun tujuan pribadi masing-masing anggota organisasi."

\section{Kompensasi}

Menurut William B. Werther dan Keith Davis (dalam Malayu Hasibuan, 2013:119):

Compensation is what employee receive in exchange of their work. Whether hourly wages or periodic salaries, the personnel department usually design and administers employee compensation. (Kompensasi adalah apa yang seorang pekerja terima sebagai balasan dari pekerjaan yang diberikannya. Baik upah per jam ataupun gaji periodik didesain dan dikelola oleh bagian personalia). 
Menurut Tohardi (dalam Edy Sutrisno, 2014:182) Mengemukakan bahwa kompensasi dihitung berdasarkan evaluasi pekerjaan, perhitungan kompensasi berdasarkan evaluasi pekerjaan tersebut dimaksudkan untuk mendapatkan pemberian kompensasi yang mendekati kelayakan (worth) dan keadilan (equity).

Menurut Edwin B. Flippo (dalam Malayu Hasibuan, 2013:119) Wages is defined as the adequate and equitable renumeration of personnel for their constribution to organizational objectives. (Upah didefinisikan sebagai balas jasa yang adil dan layak diberikan kepada para pekerja atas jasa-jasanya dalam mencapai tujuan organisasi.)

Slamet (2007: 261) "Kompensasi merupakan setiap bentuk penghargaan yang diberikan kepada pegawai sebagai balas jasa atas kontribusi yang mereka berikan kepada organisasi". Menurut Andrew F. Sikula (dalam Malayu Hasibuan, 2013:119) Kompensasi adalah segala sesuatu yang dikonstitusikan atau dianggap sebagai suatu balas jasa atau ekuivalen.

\section{Hipotesis Penelitian}

Adapun pengajuan Hipotesis dalam penelitian ini adalah sebagai berikut:

1. Terdapat pengaruh antara Kepemimpinan terhadap kinerja Pegawai.

2. Terdapat pengaruh antara motivasi terhadap kinerja Pegawai.

3. Terdapat pengaruh antara Kompensasi terhadap kinerja Pegawai.

4. Terdapat pengaruh simultan antara Kepemimpinan, motivasi dan Kompensasi terhadap kinerja Pegawai.

\section{METODE PENELITIAN DAN ANALISIS DATA}

Metode penelitian pada dasarnya merupakan cara ilmiah untuk mendapatkan data dengan tujuan dan kegunaan tertentu. Cara ilmiah kegiatan penelitian itu didasarkan pada ciri-ciri keilmuan, yaitu rasional, empiris, dan sistematis (Sugiyono 2012:2). Dalam penelitian ini menggunakan metode penelitian deskriptif dan verifikatif. Menurut Sugiyono (2012:35), penelitian deskriptif adalah penelitian yang dilakukan untuk mengetahui nilai variabel mandiri, baik satu variabel atau lebih (independent) tanpa membuat perbandingan atau menghubungkan dengan variabel yang lain. Penelitian verifikatif menurut Sugiyono (2012:3) bahwa metode penelitian kuantitatif yang digunakan untuk penelitian populasi atau sampel tertentu, dan analisis data bersifat statistik dengan tujuan untuk menguji hipotesis yang telah ditetapkan. Tujuan dari penelitian deskriptif adalah untuk memperoleh gambaran secara sistematis mengenai Kepemimpinan, motivasi kerja, Kompensasi sebagai variabel bebas dan kinerja sebagai variabel terikat, sedangkan secara verifikatif bertujuan untuk menguji hipotesis dengan perhitungan statistik.

\section{Populasi}

Populasi adalah wilayah generalisasi yang terdiri dari objek/subjek yang mempunyai kuantitas dan karakteristik tertentu yang ditetapkan oleh peneliti untuk mempelajari dan kemudian ditarik kesimpulan (Sugiono, 2012:117). Populasi dalam penelitian ini terdiri dari pegawai kantor Imigrasi Kelas II Karawang, yang terdiri dari 55 orang.

\section{Sampel}

Sugiyono (2012:81) sampel adalah bagian dari jumlah karakteristik yang dimiliki oleh populasi tersebut. Teknik pengambilan sampel yang dilakukan didalam penelitian ini adalah dengan menggunakan metode Sampling jenuh. semua anggota populasi dijadikan 
sampel untuk membuat generalisasi dengan kesalahan yang relative kecil. Dengan jumlah populasi Pegawai sebanyak 55 orang. Maka sampel yang digunakan sama yaitu 55 orang.

D. HASIL

PENELITIAN

Profil Responden

Responden dalam penelitian ini adalah Kantor Imigrasi Kelas II Karawang yang berjumlah 55 orang, dengan karakteristik sebagai berikut:

Tabel 1

Jumlah Responden Berdasarkan Jenis Kelamin

\begin{tabular}{|c|c|c|c|}
\hline No & Usia & Jumlah (orang) & Persentase (\%) \\
\hline 1 & Laki-laki & 10 & 18.2 \\
\hline 2 & Perempuan & 45 & 81.8 \\
\hline \multicolumn{2}{|c|}{ Total } & 55 & 100 \\
\hline
\end{tabular}

Tabel 2

Jumlah Responden Berdasarkan Usia

\begin{tabular}{|c|c|c|c|}
\hline No & Jenis Kelamin & Jumlah (orang) & Persentase (\%) \\
\hline 1 & $\begin{array}{c}\text { Dibawah 26 } \\
\text { Tahun }\end{array}$ & 11 & 20 \\
\hline 2 & $26-30$ Tahun & 18 & 32.7 \\
\hline 3 & 31 - 35 Tahun & 9 & 16,4 \\
\hline 4 & Diatas 36 Tahun & 17 & 30.9 \\
\hline \multicolumn{2}{|c}{ Total } & 55 & 100 \\
\hline
\end{tabular}

Tabel 3

Jumlah Responden Berdasarkan Lama Kerja

\begin{tabular}{|c|c|c|c|}
\hline No & Jenis Kelamin & Jumlah (orang) & Persentase (\%) \\
\hline 1 & $\begin{array}{c}\text { Dibawah } 1 \\
\text { Tahun }\end{array}$ & 22 & 40 \\
\hline 2 & $1-2$ Tahun & 8 & 14.5 \\
\hline 3 & $2-3$ Tahun & 10 & 18.2 \\
\hline 4 & $3-4$ tahun & 9 & 16.4 \\
\hline 5 & Diatas 4 Tahun & 6 & 10.9 \\
\hline & Total & 55 & 100 \\
\hline
\end{tabular}

Tabel 4

Jumlah Responden Berdasarkan Pendidikan

\begin{tabular}{|c|c|c|c|}
\hline No & Jenis Kelamin & Jumlah (orang) & Persentase (\%) \\
\hline 1 & SD & 0 & 0 \\
\hline 2 & SMP & 0 & 0 \\
\hline 3 & SMA & 0 & 0 \\
\hline 4 & D1 & 2 & 3.6 \\
\hline 5 & D2 & 6 & 10.9 \\
\hline 6 & D3 & 9 & 16.4 \\
\hline 7 & S1 & 36 & 65.5 \\
\hline 8 & S2 & 2 & 3.6 \\
\hline
\end{tabular}




\section{Pengujian Keabsahan Data}

\section{Uji Validitas}

Tabel 5

Hasil Uji Validitas Variabel Kepemimpinan

\begin{tabular}{|l|c|c|c|c|}
\hline \multicolumn{1}{|c|}{ Dimensi } & Pernyataan & r Hitung & Kritis & Kriteria \\
\hline Memberikan informasi & 1 & 0.604 & 0.3 & Valid \\
\hline Menjelaskan Tugas & 2 & 0.613 & 0.3 & Valid \\
\hline Motivator yang efektif & 3 & 0.499 & 0.3 & Valid \\
\hline Perencana yang tangguh & 4 & 0.470 & 0.3 & Valid \\
\hline Menerima Pendapat & 5 & 0.555 & 0.3 & Valid \\
\hline Monitoring & 6 & 0.487 & 0.3 & Valid \\
\hline Mengkoordinasikan & 7 & 0.425 & 0.3 & Valid \\
\hline Memberi Arahan & 8 & 0.597 & 0.3 & Valid \\
\hline Fasilitas Penunjang & 9 & 0.437 & 0.3 & Valid \\
\hline Objektif dan Rasional & 10 & 0.592 & 0.3 & Valid \\
\hline
\end{tabular}

Sumber: Hasil Pengolahan Data, 2017

Tabel 6

Hasil Uji Validitas Variabel Motivasi

\begin{tabular}{|l|c|c|c|c|}
\hline \multicolumn{1}{|c|}{ Dimensi } & Pernyataan & $\begin{array}{c}\text { r } \\
\text { Hitung }\end{array}$ & $\begin{array}{c}\text { r } \\
\text { Kritis }\end{array}$ & Kriteria \\
\hline Kesempatan Untuk Maju Terhadap Prestasi & 1 & 0.453 & 0.3 & Valid \\
\hline Kekompakan & 2 & 0.587 & 0.3 & Valid \\
\hline Pengembangan Karir & 3 & 0.481 & 0.3 & Valid \\
\hline Kesempatan Untuk Maju & 4 & 0.589 & 0.3 & Valid \\
\hline Umpan Balik & 5 & 0.480 & 0.3 & Valid \\
\hline Jaminan pekerjaan & 6 & 0.668 & 0.3 & Valid \\
\hline Kompensasi yang memadai & 7 & 0.438 & 0.3 & Valid \\
\hline Supervisi yang baik & 8 & 0.542 & 0.3 & Valid \\
\hline Status dan Tanggung Jawab & 9 & 0.574 & 0.3 & Valid \\
\hline Kondisi Kerja & 10 & 0.476 & 0.3 & Valid \\
\hline Peraturan yang fleksibel & 11 & 0.602 & 0.3 & Valid \\
\hline Sumber : Hasil Pengolahan Data
\end{tabular}

Sumber : Hasil Pengolahan Data, 2017

Tabel 7

Hasil Uji Validitas Variabel Kompensasi

\begin{tabular}{|l|c|c|c|c|}
\hline \multicolumn{1}{|c|}{ Dimensi } & Pernyataan & r Hitung & r Kritis & Kriteria \\
\hline Gaji & 1 & 0.323 & 0.3 & Valid \\
\hline Tunjangan Transport & 2 & 0.502 & 0.3 & Valid \\
\hline Tunjangan Kesehatan & 3 & 0.429 & 0.3 & Valid \\
\hline Asuransi & 4 & 0.668 & 0.3 & Valid \\
\hline Pakaian Dinas & 5 & 0.599 & 0.3 & Valid \\
\hline Tunjangan Pensiun & 6 & 0.495 & 0.3 & Valid \\
\hline Beasiswa Pendidikan & 7 & 0.640 & 0.3 & Valid \\
\hline Rekreasi & 8 & 0.310 & 0.3 & Valid \\
\hline Fasilitas Penunjang & 9 & 0.392 & 0.3 & Valid \\
\hline
\end{tabular}




\begin{tabular}{|l|c|c|c|c|}
\hline Tunjangan Perumahan & 10 & 0.478 & 0.3 & Valid \\
\hline Tunjangan Hari Raya & 11 & 0.439 & 0.3 & Valid \\
\hline Koperasi Pegawai & 12 & 0.557 & 0.3 & Valid \\
\hline
\end{tabular}

Sumber: Hasil Pengolahan Data, 2017

Tabel 8

Hasil Uji Validitas Variabel Kinerja

\begin{tabular}{|l|c|c|c|c|}
\hline \multicolumn{1}{|c|}{ Dimensi } & Pernyataan & r Hitung & r Kritis & Kriteria \\
\hline Pendidikan & 1 & 0.607 & 0.3 & Valid \\
\hline Pengalaman & 2 & 0.310 & 0.3 & Valid \\
\hline Skill & 3 & 0.653 & 0.3 & Valid \\
\hline Kuantitas Kerja & 4 & 0.321 & 0.3 & Valid \\
\hline Kualitas Kerja & 5 & 0.472 & 0.3 & Valid \\
\hline Pengetahuan & 6 & 0.556 & 0.3 & Valid \\
\hline Semangat Kerja & 7 & 0.844 & 0.3 & Valid \\
\hline Kreativitas & 8 & 0.600 & 0.3 & Valid \\
\hline Kehadiran & 9 & 0.441 & 0.3 & Valid \\
\hline Penyelesaian Pekerjaan & 10 & 0.673 & 0.3 & Valid \\
\hline Keramahtamahan & 11 & 0.645 & 0.3 & Valid \\
\hline Kerjasama & 12 & 0.654 & 0.3 & Valid \\
\hline
\end{tabular}

Sumber: Hasil Pengolahan Data, 2017

\section{Uji Reliabilitas}

Tabel 9

Hasil Uji Reliabilitas

\begin{tabular}{|c|l|c|c|c|}
\hline No & \multicolumn{1}{|c|}{ Variabel } & r Hitung & r Kritis & Keterangan \\
\hline 1 & Kepemimpinan $\left(\mathrm{X}_{1}\right)$ & 0.835 & 0.70 & Sangat Reliabel \\
\hline 2 & Motivasi Kerja $\left(\mathrm{X}_{2}\right)$ & 0.849 & 0.70 & Sangat Reliabel \\
\hline 3 & Kompensasi $\left(\mathrm{X}_{3}\right)$ & 0.837 & 0.70 & Sangat Reliabel \\
\hline 3 & Kinerja $(\mathrm{Y})$ & 0.879 & 0.70 & Sangat Reliabel \\
\hline
\end{tabular}

Sumber : Hasil pengolahan data, 2017

\section{Uji Normalitas}

Tabel 10

Hasil Uji Normalitas

\begin{tabular}{|l|c|c|c|}
\hline \multirow{2}{*}{ Variabel } & \multicolumn{2}{|c|}{ Kolmogrov - Smirnov } & \multirow{2}{*}{ Keterangan } \\
\cline { 2 - 3 } & r Hitung & r Kritis & \\
\hline Kepemimpinan $\left(\mathrm{X}_{1}\right)$ & 0.123 & 0.05 & Distribusi Normal \\
\hline Motivasi Kerja $\left(\mathrm{X}_{2}\right)$ & 0.103 & 0.05 & Distribusi Normal \\
\hline Kompensasi $\left(\mathrm{X}_{3}\right)$ & 0.124 & 0.05 & Distribusi Normal \\
\hline Kinerja (Y) & 0.123 & 0.05 & Distribusi Normal \\
\hline
\end{tabular}

Sumber: Hasil pengolahan data, 2017

E. PEMBAHASAN HASIL TEMUAN

PENELITIAN

Persamaan Jalur

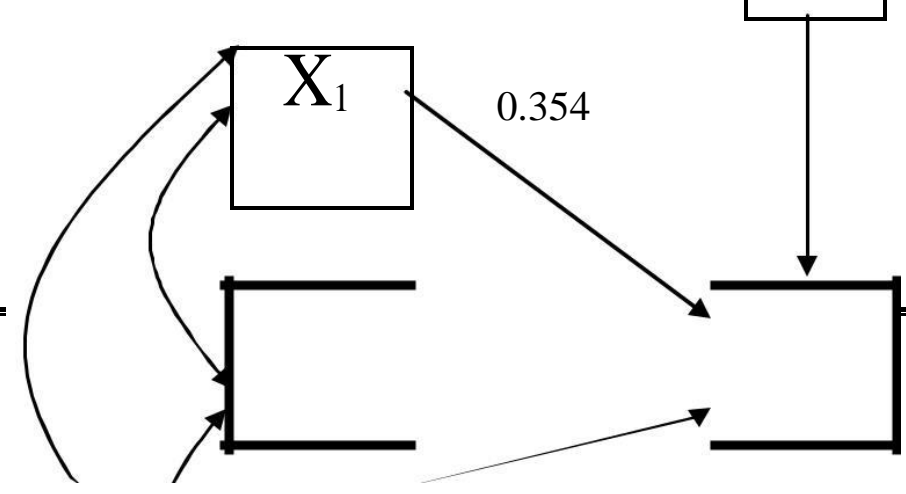




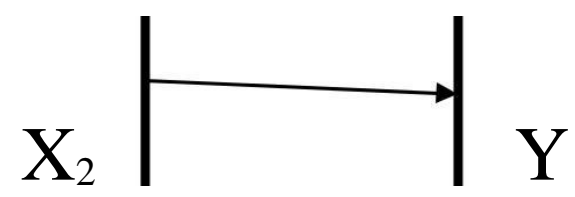


0.6140 .732

0.721

0.291

\section{Gambar 1 \\ Koefisien Jalur Variabel Displin Kerja (X1) Motivasi Kerja (X2) dan Kompensasi (X3) terhadap Kinerja Pegawai (Y)}

Berdasarkan gambar menunjukan bahwa besaran derajat positif asosiatif atau koefisien jalur variabel Kepemimpinan 0,354 lebih tinggi dari variabel Motivasi Kerja 0,339 dan Variable Kompensasi 0.291, artinya Kepemimpinan ( $\left.\mathrm{X}_{1}\right)$ lebih berpengaruh terhadap Kinerja Pegawai (Y) dibandingkan dengan Motivasi Kerja $\left(\mathrm{X}_{2}\right)$ dan Kompensasi $\left(\mathrm{X}_{3}\right)$. Adapun persamaan jalurnya adalah sebagai berikut:

$$
Y=0,354 X_{1}+0,339 X_{2}+0,291 X_{3}+\varepsilon
$$

Keterangan

$$
\begin{aligned}
& \mathrm{X}_{1}=\text { Kepemimpinan } \\
& \mathrm{X}_{2}=\text { Motivasi } \\
& \mathrm{X}_{3}=\text { Kompensasi } \\
& \mathrm{Y}=\text { Kinerja Pegawai } \\
& \varepsilon \quad=\text { Variabel lain yang tidak diukur, tetapi mempengaruhi } \mathrm{Y}
\end{aligned}
$$

\section{Pengujian Hipotesis}

Pengaruh secara Parsial Kepemimpinan (X1) terhadap Kinerja Pegawai (Y)

Pengaruh Kepemimpinan secara parsial terhadap Kinerja Pegawai dapat diketahui melalui pengujian statistik dengan menggunakan hipotesis sebagai berikut :

$H_{0}: \rho x_{1} x_{2}=0$ Kepemimpinan tidak berpengaruh terhadap kinerja

$H_{1}: \rho x_{1} x_{2} \neq 0$ Kepemimpinan berpengaruh terhadap kinerja

Kriteria Uji : Tolak $\mathrm{H}_{\mathrm{O}}$ jika Sig. $<\alpha$ atau thitung $>$ tabel

Untuk pengaruh Kepemimpinan secara parsial terhadap Kinerja Pegawai dengan tingkat signifikan $(\alpha)=5 \%$, degree of freedom $(\mathrm{df})=(\mathrm{n}-2)=55-2=53$ diperoleh tabel

$=1,674$. Berdasarkan tabel 4.61 di atas, menunjukan bahwa thitung $=3.223$ dan sig. 0,002. Pengaruh $\mathrm{X}_{1}$ secara Parsial terhadap $\mathrm{Y}$ diperlihatkan pada tabel 4.67 sebagai berikut :

Tabel 11 
Pengaruh Parsial

Kepemimpinan $\left(\mathrm{X}_{1}\right)$ terhadap Kinerja Pegawai $(\mathrm{Y})$

\begin{tabular}{|c|c|c|c|c|c|}
\hline Structural & Sig. & $\boldsymbol{\alpha}$ & thitung & t tabel & Kesimpulan \\
\hline pyx 1 & 0,002 & 0,05 & 3.223 & 1,674 & $\mathrm{H}_{\mathrm{O}}$ ditolak \\
\hline
\end{tabular}

Sumber : Hasil Pengolahan Data, 2017

Tabel diatas menunjukan bahwa nilai sig. $(0,002)>\alpha(0,05)$ dan thitung $(3.223)>t_{\text {tabel }}$ $(1,674)$ maka $\mathrm{H}_{\mathrm{O}}$ ditolak. Dengan demikian dapat disimpulkan bahwa Kepemimpinan secara parsial berpengaruh positif dan signifikan terhadap Kinerja Pegawai.

\section{Pengaruh Parsial Motivasi Kerja (X2) terhadap Kinerja Pegawai (Y)}

Pengaruh Motivasi Kerja secara parsial terhadap Kinerja Pegawai dapat diketahui melalui pengujian statistik dengan menggunakan hipotesis sebagai berikut :

$H_{0}$ : Motivasi Kerja tidak berpengaruh terhadap kinerja

$H_{1}$ : Motivasi Kerja berpengaruh terhadap kinerja

Kriteria Uji : Tolak $\mathrm{H}_{\mathrm{o}}$ jika Sig. $<\alpha$ atau thitung $>$ tabel

Untuk pengaruh Motivasi Kerjasecara parsial terhadap Kinerja Pegawai dengan tingkat signifikan $(\alpha)=5 \%$, degree of freedom $(\mathrm{df})=(\mathrm{n}-2)=55-2=53$ diperoleh $\mathrm{t}_{\text {tabel }}=$ 1,674 .

Berdasarkan tabel 4.61 di atas, menunjukan bahwa thitung $=\quad 3.267$ dan sig. 0,000. Pengaruh $\mathrm{X}_{2}$ secara parsial terhadap $\mathrm{Y}$ diperlihatkan pada tabel sebagai berikut:

\section{Tabel 12}

\section{Pengaruh Parsial}

Motivasi Kerja ( $\left.\mathrm{X}_{2}\right)$ terhadap Kinerja Pegawai

(Y)

\begin{tabular}{|c|c|c|r|c|c|}
\hline Structural & Sig. & $\boldsymbol{\alpha}$ & thitung & ttabel & Kesimpulan \\
\hline Pyx2 & 0,002 & 0,05 & 3. & 1,674 & H Hoditolak $^{267}$ \\
\hline
\end{tabular}

Sumber : Hasil Pengolahan Data, 2017

Tabel diatas menunjukan bahwa nilai sig. $(0,002)<\alpha(0,05)$ dan thitung $(3.267)>t_{\text {tabel }}$ $(1,674)$ maka $\mathrm{H}_{\mathrm{O}}$ ditolak. Dengan demikian dapat disimpulkan bahwa Motivasi Kerjasecara parsial berpengaruh positif dan signifikan terhadap Kinerja Pegawai.

\section{Pengaruh Parsial Kompensasi (X3) terhadap Kinerja Pegawai (Y)}

Pengaruh Kompensasi secara parsial terhadap Kinerja Pegawai dapat diketahui melalui pengujian statistik dengan menggunakan hipotesis sebagai berikut :

$H_{0}$ : Kompensasi tidak berpengaruh terhadap kinerja

$H_{1}$ : Kompensasi berpengaruh terhadap kinerja

Kriteria Uji : Tolak $\mathrm{H}_{\mathrm{o}}$ jika Sig. $<\alpha$ atau thitung $>\mathrm{t}_{\text {tabel }}$

Untuk pengaruh Kompensasi secara parsial terhadap Kinerja Pegawai dengan tingkat signifikan $(\alpha)=5 \%$, degree of freedom $(\mathrm{df})=(\mathrm{n}-2)=55-2=53$ diperoleh $\mathrm{t}$ tabel $=$ 1,674. Berdasarkan tabel 4.61 di atas, menunjukan bahwa thitung $=3.022$ dan sig. 0,004. Pengaruh $\mathrm{X}_{2}$ secara parsial terhadap $\mathrm{Y}$ diperlihatkan pada tabel sebagai berikut:

Tabel 4.13

Pengaruh Parsial

Kompensasi (X3) terhadap Kinerja Pegawai (Y)

\begin{tabular}{|r|r|r|r|r|r|}
\hline Structural & Sig. & $\alpha$ & thitung & ttabel & Kesimpulan \\
\hline
\end{tabular}




\begin{tabular}{|l|r|r|r|r|r|}
\hline Pyx3 & 0,004 & 0,05 & 3.022 & 1,674 & $\mathrm{H}_{\mathrm{O}}$ ditolak \\
\hline
\end{tabular}

Sumber : Hasil Pengolahan Data, 2017

Tabel 4.69 diatas menunjukan bahwa nilai sig. $(0,004)<\alpha(0,05)$ dan thitung (3.022) > t tabel $(1,674)$ maka $\mathrm{H}_{\mathrm{O}}$ ditolak. Dengan demikian dapat disimpulkan bahwa Kompensasi secara parsial berpengaruh positif dan signifikan terhadap Kinerja Pegawai.

\section{Pengaruh Variable Secara Simultan}

Pengaruh Kepemimpinan $\left(\mathrm{X}_{1}\right)$, Motivasi Kerja $\left(\mathrm{X}_{2}\right)$ dan Kompensasi $\left(\mathrm{X}_{3}\right)$ secara simultan (keseluruhan) terhadap Kinerja Pegawai (Y) dapat diketahui melalui pengujian statistik dengan menggunakan hipotesis sebagai berikut:

$H_{0}$ : Kepemimpinan, Motivasi Kerja dan Kompensasi secara simultan tidak berpengaruh terhadap kinerja

$H_{1}$ : Kepemimpinan, Motivasi Kerja dan Kompensasi secara simultan berpengaruh terhadap kinerja.

Kriteria Uji : Tolak $\mathrm{H}_{\mathrm{O}}$ jika Sig. $<\alpha$ atau thitung $>\mathrm{f}_{\text {tabel }}$

Untuk pengaruh Kepemimpinan, Motivasi Kerjadan Kompensasi secara simultan terhadap Kinerja Pegawai dengan tingkat signifikan $(\alpha)=5 \%$, degree of freedom $(\mathrm{df})=$ $(\mathrm{n}-2)=55-2=53$, diperoleh $\mathrm{f}_{\text {tabel }}=2.53$. Sedangkan $\mathrm{f}_{\text {hitung }}$ dapat dilihat pada tabel di bawah ini :

Tabel 14

Hasil Perhitungan Nilai F

\begin{tabular}{|rl|r|r|r|r|r|}
\hline \multicolumn{1}{|c|}{ ANOVA $^{\mathbf{a}}$} & & \\
Model & & Sum of Squares & df & $\begin{array}{c}\text { Mean } \\
\text { Square }\end{array}$ & F & Sig. \\
\hline 1 & Regression & 2191.259 & 3 & 730.420 & 63.151 & $.000^{\mathrm{b}}$ \\
& Residual & 589.875 & 51 & 11.566 & & \\
& Total & 2781.134 & 54 & & & \\
\hline
\end{tabular}

a. Dependent Variable: KINERJA

b. Predictors: (Constant), KOMPENSASI, KEPEMIMPINAN, MOTIVASI

Sumb

er : Hasil Pengolahan Data, 2017

Berdasarkan tabel di atas, menunjukan bahwa $f_{\text {hitung }}=63.151$ dan sig. 0,000. Pengaruh Kepemimpinan (X1), Motivasi Kerja (X2) dan Kompensasi (X3) secara simultan terhadap Kinerja Pegawai (Y) diperlihatkan pada tabel di bawah ini :

Tabel 15

Pengaruh Simultan Kepemimpinan (X1), Motivasi Kerja (X2)

Dan Kompensasi $\left(\mathbf{X}_{3}\right)$ terhadap Kinerja Pegawai $(\mathbf{Y})$

\begin{tabular}{|c|c|c|c|r|c|}
\hline Structural & Sig. & $\boldsymbol{\alpha}$ & fhitung & ftabel & Kesimpulan \\
\hline Pyx $1, \mathrm{x} 2, \mathrm{X} 3$ & 0,000 & 0,05 & 63.151 & 2.53 & $\mathrm{H}_{\mathrm{O}}$ ditolak \\
\hline
\end{tabular}

Sumber : Hasil Pengolahan Data, 2017

Tabel diatas menunjukan bahwa nilai sig. $(0,000)<\alpha(0,05)$ dan $f_{\text {hitung }}(63.151)>f_{\text {tabel }}$ (2.53) maka $\mathrm{H}_{\mathrm{O}}$ ditolak. Dengan demikian dapat disimpulkan bahwa Kepemimpinan, Motivasi Kerja dan Kompensasi secara simultan berpengaruh positif dan signifikan terhadap Kinerja Pegawai. 


\section{F. SIMPULAN}

Berdasarkan hasil penelitian, pengumpulan data dan pembahasan yang dilakukan peneliti pada Kantor Imigrasi Kelas II Karawang maka dapat di ambil kesimpulan sebagai berikut :

1. Kinerja Pegawai pada Kantor Imigrasi Kelas II Karawang sudah baik, karena indikator yang diteliti dengan total skor sebesar 2.537 dan nilai rata-rata yaitu 211.4 yang berada pada rentang skala 187.1-231.1 berada pada kriteria setuju.

2. Kepemimpinan pada Kantor Imigrasi Kelas II Karawang sudah baik, karena Indikator yang diteliti dengan total skor sebesar 2.079 dan nilai rata-rata yaitu 207.9, yang pada rentang skala 187.1-231.1 berada pada kriteria setuju.

3. Motivasi Kerja pada Kantor Imigrasi Kelas II Karawang yang diberikan kepada pegawai sudah baik, karena indikator yang diteliti dengan total skor sebesar 2.228 dan nilai rata-rata yaitu 202.6 yang berada pada rentang skala 187.1-231.1.

4. Kompensasi pada Kantor Imigrasi Kelas II Karawang sudah baik karena indikator yang diteliti dinyatakan setuju oleh responden dengan total skor 2.449 dengan ratarata 204.1, yang berada pada rentang skala 187.1-231.1.

5. Terdapat pengaruh parsial antara Kepemimpinan terhadap Kinerja sebesar $27.6 \%$ dan terdapat pengaruh parsial antara Motivasi Kerja terhadap Kinerja sebesar 27.4\% kemudian pengaruh parsial Kompensasi Terhadap Kinerja sebesar $21.9 \%$. Hal ini mendukung penelitian yang telah dilakukan oleh Rahmat Sugianto (2010), Windy Aprilia Murty dan Gunasti Hudiwinarsih (2012), Ririvega kasenda (2013), Agiel Puji Damayanti, Susilaningsih, Sri Sumaryati (2013), Ni Ketut Ayu Juli Astuti dan I Nyoman Sudharma (2013) dan Ferry Setiawan dan A. A. Sg. Kartika Dewi (2014).

6. Kepemimpinan, Motivasi Kerja dan Kompensasi secara simultan berpengaruh positif dan signifikan terhadap Kinerja Pegawai. Total pengaruh yang disebabkan Kepemimpinan $\left(\mathrm{X}_{1}\right)$, Motivasi Kerja $\left(\mathrm{X}_{2}\right)$ dan Kompensasi $\left(\mathrm{X}_{3}\right)$ terhadap Kinerja Pegawai (Y) yaitu sebesar 0,769 atau $76,9 \%$ adapun pengaruh variabel lain diluar model adalah sebesar 0,231 atau 23,1\%. Hal ini mendukung penelitian Agiel Puji Damayanti, Susilaningsih, Sri Sumaryati (2013), Windy Aprilia Murty dan Gunasti Hudiwinarsih (2012) dan Ni Ketut Ayu Juli Astuti dan I Nyoman Sudharma (2013).

\section{G. SARAN}

Berdasarkan dari hasil penelitian yang dilakukan dan dalam kesempatan ini penulis akan sedikit memberikan beberapa saran, diharapkan dapat menjadi bahan masukan dan bahan pertimbangan bagi Kantor Imigrasi Kelas II Karawang yang sifatnya untuk kemajuan perusahaan tersebut:

1. Diharapkan Kantor Imigrasi karawang terus meningkatkan kinerja pegawai Sehingga dalam pelayanan terhadap masyarakat dapat lebih baik lagi.

2. Diharapkan pimpinan kantor imigrasi karawang terus meningkatkan Kepemimpinan karena dengan kepemimpinan yang baik maka akan tercipta kondisi kerja yang kondusif dan harmonis.

3. Diharapkan kantor imigrasi karawang dapat terus meningkatkan Motivasi Kerja pegawai agar pegawai dapat bekerja secara optimal.

4. Diharapkan kantor imigrasi karawang dapat terus meningkatkan Kompensasi yang diberikan agar pegawai lebih nyaman dalam bekerja. 
5. Hasil penelitian menunjukan bahwa kinerja pegawai, kepemimpinan, motivasi kerja dan kompensasi sudah baik, tetapi masih belum optimal karena masih ada indikator yang memiliki skor terendah. Diharapkan kantor imigrasi karawang terus mempertahankan indikator yang sudah mendapatkan presentasi yang baik serta meningkatkan indikator yang masih kurang yaitu pada indikator kehadiran, Perencana yang tangguh, kondisi kerja dan Rekreasi. Dengan cara mengadakan family gathering yang dijadwalkan secara rutin sehingga para pegawai dapat lebih baik dalam bekerja. Kemudian seorang pimpinan perlu memiliki fundamental interpersonal skill yang kuat, kemampuan manajerial yang baik, kompetensi interpersonal dan leadership yang ethical sehingga dapat tercipta kondisi kerja yang harmoni dan kondusif.

6. Diharapkan kantor imigrasi kelas II Karawang dapat mempertahankan indikator yang memiliki skor tertinggi dibandingkan indikator lain, pada variable kinerja pegawai skor tertinggi yaitu pada indikator Semangat kerja, untuk variable kepemimpinan pada indikator motivator yang efektif, kemudian variable motivasi kerja yaitu pada indikator penghargaan terhadap prestasi sedangkan pada variable kompensasi yaitu pada indikator beasiswa pendidikan. Dengan mempertahankan beberapa indikator tersebut kinerja pegawai dapat lebih baik lagi dalam melayani kebutuhan masyarakat.

\section{H. DAFTAR}

\section{PUSTAKA I.}

Buku Dan Jurnal

Agiel Puji Damayanti, Susilaningsih dan Sri Sumaryati. 2013. Pengaruh kompensasi dan motivasi kerja terhadap kinerja Karyawan Perusahaan Daerah Air Minum (PDAM) surakarta. Jurnal Jupe UNS, Vol 2, No 1, Universitas Sebelas Maret (Diakses Tanggal 5 Mei 2017, 01.12)

Ayu Desi Indrawati, 2016. Pengaruh kepuasan kerja terhadap kinerja karyawan dan kepuasan pelanggan pada rumah sakit swasta Di kota Denpasar. Jurnal Manajemen, Strategi Bisnis, dan Kewirausahaan Vol. 7, No. 2, Universitas Udayana, Bali. (Diakses Tanggal 05 Mei 2017, 10:53).

Ambar Teguh Sulistiyani dan Rosidah. 2009. Manajemen Sumber Daya Manusia. Graha Ilmu, Yogyakarta

Bangun, Wilson.2012.Manajemen Sumber Daya Manusia. Erlangga.

Jakarta Dessler, Gary. 2011. Manajemen Sumber Daya Manusia. Indeks, Jakarta

Didik Hadiyatno. 2012. Pengaruh Kompetensi, Kompensasi, Dan Kepuasan Kerja Terhadap Kinerja Karyawan Pada PT. Ciomas Adisatwa Balikpapan. Jurnal Manajemen Pendidikan Volume 24, Nomor 5, Maret 2015, SMAN 5 Bandung (Diakses tanggal 6 Mei 2017, 02.04)

Fahmi, Irham, 2011. Manajemen Kinerja. Edisi ke Satu, Penerbit Alfabeta, Bandung. Fatoni, Abdurahmat. 2006. Manajemen Sumber Daya Manusia. Rineka Cipta Bandung

Ferry Setiawan dan A. A. Sg. Kartika Dewi. 2013. Pengaruh Kepuasan Kerja Terhadap Kinerja Karyawan Dan Kepuasan Pelanggan Pada Rumah Sakit Swasta Di Kota Denpasar. Jurnal Manajemen, Strategi Bisnis, dan Kewirausahaan Vol. 3, No. 5, Universitas Udayana, Bali (Diakses tangal 6 Mei 2017, 01:16) 
Grant, AE dkk. 2008. Communication Technology Update And Fundamental. Focal Press. Boston

Handoko, T Hani. 2008. Manajemen. Edisi 2. BPFE, Yogyakarta.

2012. Manajemen. BPFE, Yogyakarta.

Hasibuan, Malayu. S. P. 2009. Manajemen dasar Pengertian dan Masalah Edisi Revisi . Bumi Aksara. Jakarta 2013. Manajemen dasar Pengertian dan Masalah Edisi Revisi

. Bumi Aksara. Jakarta

Indriyo, Gitosudarmo. 2008. Manajemen Pemasaran. BPFE. Yogyakarta

Jonathan Sarwono. Metode Penelitian Kuantitatif dan Kualitatif. Penerbit Graha Ilmu. Yogyakarta.

Kadarisman, M. 2012. Manajemen Pengembangan Sumber Daya Manusia. Rajawali Press. Jakarta

Mangkunegara, A.A Anwar Prabu. 2008. Manajemen Sumber Daya

Manusia Perusahaan. Remaja Rosdakarya. Bandung . 2011. Manajemen Sumber Daya

Manusia Perusahaan. Bandung: Remaja Rosdakarya.

Manullang. 2012.Dasar-Dasar Manajemen. UGM Gajah Mada University Press. Yogyakarta

Masydzulhak, Hapzi Ali dan Leni Dewi Anggraeni. 2016. The Influence of work Motivation and Job Satisfaction on Employee Performance and Organizational Commitment Satisfaction as an Intervening Variable in PT. Asian Isuzu Casting Center. Quest Journals Journal of Research in Business and Management Volume 4 Issue 10(2016) pp: 01-10 ISSN(Online) 23473002 Mercubuana University. (Diakses Tanggal 5 Mei 2017. 05.02)

Mathis LR dan JH Jackson. 2012. Human resource Management. Salemba Empat. Jakarta

Nawawi, Hadari. 2008. Manajemen Sumber Daya Manusia Untuk Bisnis Yang Kompetitif. Gajah mada University Press. Yogyakarta

Nelson, DL dan JC Quick. 2006. Organizational Behavior Foundation Realities and Challenges, Thompson South Western. United States Of America

Ni Ketut Ayu Juli Astuti danI Nyoman Sudharma. 2013. Pengaruh Kompensasi Dan Motivasi Terhadap Kepuasan Dan Kinerja Karyawan Pada Hotel Bakung's Beach Cottages Kuta-Bali. Jurnal Bisnis dan Manajemen Eksekutif Vol. 1 No. 2, Universitas Terbuka. (Diakses Tanggal 5 Mei 2017, 12:59)

Pasolong, Harbani. 2011. Teori Administrasi Publik. Alfabeta. Jakata

Ririvega Kasenda. 2013. Kompensasi dan motivasi pengaruhnya terhadap kinerja karyawan pada pt. Bangun wenang beverages company Manado. Jurnal EMBAVol.1 No.3, Universitas Sam Ratulangi (Diakses Tanggal 5 Mei 2017, 02:18)

Rivai,Veithzal. 2010. Manajemen Sumber Daya Manusia untuk Perusahaan. Rineka Cipta. Jakarta.

2012. Manajemen Sumber Daya Manusia untuk Perusahaan. Rineka Cipta. Jakarta

Robbins, Stephen P \& Mary Coulter, 2010. Manajemen Edisi 10. Penerbit Erlangga, 
Jakarta.

Sembiring, Masana. 2012. Budaya dan Kinerja Organisasi. Focusmedia: Bandunng Sugiyono, 2012. Metode Penelitian Kuantitatif, Kualitatif, dan R \& D. Penerbit Alfabeta, Bandung.

, 2013. Metode Penelitian Kuantitatif, Kualitatif, dan R \& D. Penerbit Alfabeta, Bandung.

Susiati Purwaning Utami. 2010. pengaruh kepemimpinan, motivasi dan komunikasi interpersonal terhadap kinerja karyawan pada biro perjalanan wisata"panen tour". Jurnal Ilmiah WIDYA, Volume 3 Nomor 1 Januari-Agustus 2015, ISSN 2337-6686, STIA Yappann. (Diakses Tanggal 6 Mei 2017. 00.02)

Silalahi, Uber. 2012. Asas-asas Manajemen. Refika Aditama. Bandung.

Simamora,Henry. 2011. Manajemen Sumber Daya Manusia. Edisi Ke-3. STIE YKPN. Yogyakarta

Sinambela, Poltak Lijan. 2012. Kinerja Pegawai Teori Pengukuran dan Implikasi. Yogyakarta: Graha Ilmu

Siswanto. 2010. Pengantar Manajemen. Cetakan 6. Bumi Aksara. Jakarta Sopiah. 2008. Perilaku Organisasi. Edisi kesatu. Andi. Yogyakarta Sutrisno, Edy. 2009. Manajemen Sumber Daya Manusia. Kencana. Jakarta Suwatno \& Donni Juni Priansa. 2011. Manajemen SDM Dalam Organisasi Publik dan Bisnis, Alfabeta, Bandung.

Titi Riansari. 2011. Pengaruh Kompensasi dan Lingkungan Kerja terhadap Kepuasan Kerja dan Kinerja Karyawan (Studi Kasus PT Bank TabunganPensiunan

Nasional,Tbk Cabang Malang). Jurnal TERAKREDITASI SK DIRJEN DIKTI NO. 66b/DIKTI/KEP/2011, ISSN: 1693-5241, Universitas Brawijaya. (Diakses Tanggal 6 Mei 2017. 04:01)

Usman, Husaini. 2011. Manajemen: Teori, Praktik Dan Riset Pendidikan. Bumi Aksara. Jakarta.

Wibowo. 2012. Manajemen Kinerja (Edisi Ke 3). Rajawali Press. Jakarta Wirawan. 2009. Evaluasi Kinerja Sumber Daya Manusia: Teori Aplikasi Penelitian.

Salemba Empat, Jakarta

Yani, Asep Tapip. 2011. Manajemen Sumber Daya Manusia. Humaniora. Bandung

\section{Peraturan, Kebijakan dan Buku Pedoman}

1. Buku Pedoman Penyusunan Tugas Akhir Mahasiswa S2 Manajemen. 2017. Fakultas Ekonomi Universitas Singaperbangsa Karawang 